\title{
Apparent survival of the salamander Salamandra salamandra is low because of high migratory activity Benedikt R Schmidt ${ }^{1,2}$, Michael Schaub ${ }^{3,4}$ and Sebastian Steinfartz*5
}

\author{
Address: ${ }^{1 Z}$ Zoologisches Institut, Universität Zürich, Winterthurerstrasse 190, 8057 Zürich, Switzerland, ${ }^{2}$ KARCH, Passage Maximilien-de-Meuron \\ 6, 2000 Neuchâtel, Switzerland, ${ }^{3}$ Conservation Biology, Zoologisches Institut, Universität Bern, Baltzerstrasse 6, 3012 Bern, Switzerland, \\ ${ }^{4}$ Schweizerische Vogelwarte, 6204 Sempach, Switzerland and ${ }^{5}$ University of Bielefeld, Department of Animal Behavior, Morgenbreede 45, 33615 \\ Bielefeld, Germany \\ Email: Benedikt R Schmidt - bschmidt@zool.uzh.ch; Michael Schaub - michael.schaub@nat.unibe.ch; \\ Sebastian Steinfartz* - sebastian.steinfartz@uni-bielefeld.de \\ * Corresponding author
}

Published: 6 September 2007

Frontiers in Zoology 2007, 4:19 doi:10.1186/1742-9994-4-19
Received: II May 2007

Accepted: 6 September 2007

This article is available from: http://www.frontiersinzoology.com/content/4/1/19

(c) 2007 Schmidt et al; licensee BioMed Central Ltd.

This is an Open Access article distributed under the terms of the Creative Commons Attribution License (http://creativecommons.org/licenses/by/2.0), which permits unrestricted use, distribution, and reproduction in any medium, provided the original work is properly cited.

\begin{abstract}
Background: Understanding the demographic processes underlying population dynamics is a central theme in ecology. Populations decline if losses from the population (i.e., mortality and emigration) exceed gains (i.e., recruitment and immigration). Amphibians are thought to exhibit little movement even though local populations often fluctuate dramatically and are likely to go exinct if there is no rescue effect through immigration from nearby populations. Terrestrial salamanders are generally portrayed as amphibians with low migratory activity. Our study uses demographic analysis as a key to unravel whether emigration or mortality is the main cause of "losses" from the population. In particular, we use the analysis to challenge the common belief that terrestrial salamanders show low migratory activity.
\end{abstract}

Results: The mark-recapture analysis of adult salamanders showed that monthly survival was high (> 90\%) without a seasonal pattern. These estimates, however, translate into rather low rates of local annual survival of only $\sim 40 \%$ and suggest that emigration was important. The estimated probability of emigration was $49 \%$.

Conclusion: Our analysis shows that terrestrial salamanders exhibit more migratory activity than commonly thought. This may be due either because the spatial extent of salamander populations is underestimated or because there is a substantial exchange of individuals between populations. Our current results are in line with several other studies that suggest high migratory activity in amphibians. In particular, many amphibian populations may be characterized by high proportions of transients and/or floaters.

\section{Background}

Local population dynamics are a function of survival and reproductive rates within a focal area and rates of dispersal into and out of that area. The spatial extent and the degree of isolation of a local population have an impact on local population dynamics and hence these factors need to be considered in studies about local population dynamics [1$3]$. Only if we understand the patterns in vital rates birth, death, emigration and immigration - and the proc- 
esses that cause these patterns, then can we understand the ecology and evolutionary dynamics of a species.

The four main drivers of population change can be conveniently summarized as gains (birth and immigration) and losses (mortality and emigration). Theory for species with complex life cycles, such as amphibians, predicts and empirical studies of amphibian populations confirm that a change in "losses" has a stronger impact on amphibian population growth rate than a same change in the "gains" $[4,5]$. We use data from a two-year mark-recapture study of adult fire salamanders (Salamandra salamandra) to address two questions on how the two types of "losses", mortality and emigration, affect amphibian population dynamics. First, we ask when losses occur, because the timing and type of losses may affect population dynamics [6]. Second, terrestrial salamanders like Salamandra salamandra are generally considered to display strong site fidelity to small home ranges and move little during an individual's adult life [7-9]. This classic view, however, is beginning to change [10-14]. Therefore, we ask what proportion of salamanders emigrate from the study area and whether the emigration component of losses from the population could have a large influence on population change.

Our first question regarding losses is whether survival varies seasonally with a difference in adult survival between summer - when individuals are active - and winter, when individuals are inactive. Seasonal variation provides information when most mortality occurs during the annual cycle and therefore indicates at which time mechanisms of population regulation operate. The distinction between winter and summer mortality is crucial as they are likely influenced by different factors. Winter survival is almost certainly determined by extrinsic environmental factors such as weather conditions [15]. Summer survival, in contrast, could be more affected by either intrinsic factors that may depend on population density or behaviour. Accordingly, summer and winter survival may be under hard or soft selection, respectively, and this may profoundly affect population dynamics [6].

The second issue we address is migration. Migration of amphibians has received relatively little attention in the past, but it seems that it is probably far more important than hitherto thought for the dynamics of populations ranging from patchy to metapopulations [10]. At small spatial scales, movement of individuals determines the spatial extent of a population and patterns of genetic differentiation within and among demes. We are only beginning to understand that amphibian populations have a much larger spatial extent than it is commonly thought [10-14]. At larger spatial scale, migration likely affects the persistence of populations and metapopulations.
Amphibian populations are well-known for large fluctuations in abundance [16]. With such large fluctuations, individual populations have a high risk of extinction $[17,18]$. Thus, migration between populations is essential to prevent local extinction (i.e., the rescue effect [19]). Salamandra salamandra is well suited to address these questions because until recently it was considered as a text book example for strong site fidelity and small home ranges [7-9].

Here, we report estimates of survival of adult salamanders that are remarkably low in comparison with estimates from previous studies. We then show that low apparent survival is likely to be the consequence of high emigration rates, thus confirming the emerging view that amphibians are far more vagile than commonly assumed.

\section{Results}

We captured 86 individuals of which 41 individuals had been recaptured at least once. A summary of the data is provided in Table 1 . The general model with timedependent apparent survival and recapture probabilities $\left(\phi_{\mathrm{t}}, p_{\mathrm{t}}\right)$ fitted the data well (goodness-of-fit test with UCARE [19]: $\chi^{2}=1.574, \mathrm{df}=4, P=0.813$ ). Thus, there is no evidence for heterogeneity in detection probabilities (which might have been caused by salamanders that inhabit home ranges close to the edge of the study area and that may temporarily leave the study area).

Due to the relatively small sample size and the short duration of the study, there was model selection uncertainty, i.e., several models explained well the information in the data (Table 2). Models with fewer parameters had generally higher support from the data than more complex models. Still, the poor fit of model $(\phi, p)$ indicates that there was structure in the data. Instead of focusing on a single best model for inference, we computed model averaged parameter estimates [21]. Model averaged monthly survival probabilities were greater than 0.9 and increased

Table I: Summary of the capture-recapture data of $\mathbf{8 6}$ individual fire salamanders from Ellhauser Forest (Germany) collected between $200 \mathrm{I}$ and 2003 (m-array format, [47]).

\begin{tabular}{cccccc}
\hline & & \multicolumn{4}{c}{ Number of recaptures } \\
\cline { 3 - 6 } Occasion & Releases & Sept. & May & Sept. & May \\
& & 2001 & 2002 & 2002 & 2003 \\
\hline May 2001 & 80 & 17 & 17 & 2 & 1 \\
Sept. 2001 & 17 & & 11 & 0 & 0 \\
May 2002 & 34 & & & 12 & 5 \\
Sept. 2002 & 14 & & & & 3 \\
\hline
\end{tabular}

For each capture occasion the number of released individuals and the number of recaptured individuals of each release cohort per occasion is shown. 
initially but then dropped during the last winter (Figure $1)$.

We calculated the annual survival probability as the product of the monthly survival probabilities. We assumed that the summer period lasts 5 months (May to September) and the winter period 7 months (October to April), thus annual apparent survival probability resulted as $\phi_{\text {summer }}{ }^{5 *} \phi_{\text {winter }}{ }^{7}$. The corresponding standard error was calculated by applying the delta method [22]. The annual apparent survival probabilities were 0.41 (SE: 0.16) and 0.39 (SE: 0.28) for the two years, respectively.

Our estimates of apparent survival are confounded with permanent emigration. That is, apparent survival is equal to true survival multiplied by ( 1 - probability of emigration) [23]. We can thus calculate the probability of emigration as 1 - (apparent survival/true survival). Based on the survival estimates for Salamandra salamandra in a very similar habitat presented in [5], we assumed that true survival would be around 0.8 . This yielded an estimate of the annual probability of emigration of 0.49 .

Recapture probabilities showed a clear seasonal pattern. They were low during autumn and high during the spring capture sessions (Fig. 2). Such a pattern may lead to erroneous conclusions if recapture probabilities are not accounted for in the analysis [24].

\section{Discussion}

The mark-recapture analysis of adult fire salamanders showed that monthly apparent survival varied through time. Estimates of apparent annual survival were remarkably low and suggest that emigration from the study site is

Table 2: Modelling monthly apparent survival $(\phi)$ and recapture probabilities $(p)$ of fire salamanders from Ellhauser Forest (Germany).

\begin{tabular}{lcccc}
\hline Model & Deviance & $\mathrm{K}$ & $\Delta \mathrm{AICc}$ & $w_{\mathrm{i}}$ \\
\hline$\phi_{\mathrm{t}}, p_{\mathrm{s}}$ & 14.93 & 6 & 0.00 & 0.33 \\
$\phi_{.}, p_{\mathrm{t}}$ & $17.5 \mathrm{I}$ & 5 & 0.40 & 0.27 \\
$\phi, p_{\mathrm{s}}$ & 23.13 & 3 & 1.76 & 0.13 \\
$\phi_{\mathrm{t}}, p_{\mathrm{t}}$ & 14.92 & 7 & 2.21 & 0.11 \\
$\phi_{\mathrm{s}}, p_{\mathrm{t}}$ & 17.44 & 6 & 2.52 & 0.09 \\
$\phi_{\mathrm{s}}, p_{\mathrm{s}}$ & 23.10 & 4 & 3.85 & 0.05 \\
$\phi_{\mathrm{s}}, P_{.}$ & 30.13 & 3 & 8.76 & 0.00 \\
$\phi_{\mathrm{t}}, P_{.}$ & 26.67 & 5 & 9.56 & 0.00 \\
$\phi, P$. & 36.60 & 2 & 13.14 & 0.00 \\
\hline
\end{tabular}

The model subscript $t$ refers to time dependence (i.e., different in each year and season), $s$ denotes a seasonal effect (i.e., different survival during summer and winter months), and a dot (.) denotes constancy. Table entries are deviance (Deviance) of each model, the number of estimated parameters $(K)$, the difference of the AICc value of the current model and of the best model $(\triangle A I C c)$, and the AICc weight $\left(w_{i}\right)$.

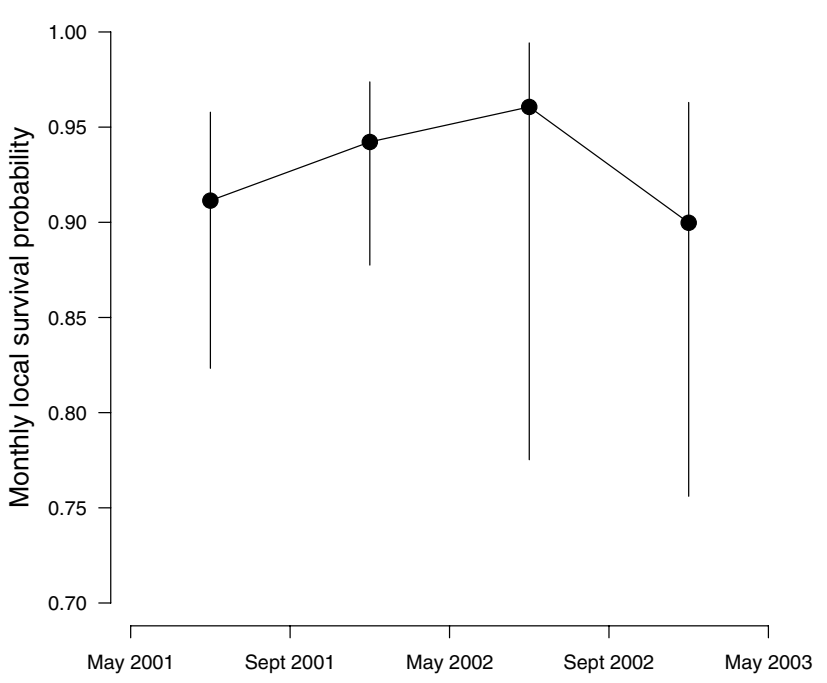

Figure I

Model averaged monthly apparent survival probability of Salamandra salamandra from Ellhauser Forest (Germany). The vertical lines show the limits of the unconditional $95 \%$ confidence intervals.

strong: about $50 \%$ of the salamanders emigrated from the study area. Our results corroborate the emerging view that amphibians are far more mobile than commonly thought $[10-14,16,19]$.

Apparent monthly survival varied from month to month but not seasonally. Reading [15] reported that survival of common toads was a function of winter weather. In salamanders, however, there is apparently no season during which mortality is elevated [2]. It may be that different factors affect survival in different months but their net effect on survival appears to be the same. Hence, our study does not reveal whether extrinsic factors, such as harshness of winters, or behaviourally- or density-mediated factors during the activity period primarily affect salamander survival and consequently population dynamics. We believe that further study of seasonal variation in salamanders is warranted because different factors may exert soft or hard selection on salamanders that in turn determine whether populations are regulated locally or at the metapopulation level [6].

Annual apparent survival of the Ellhauser forest salamander population was considerably lower than other estimates [5]. While there is certainly geographic variation in life history traits [25], survival rate of the Ellhauser forest population is half that of another well studied German 


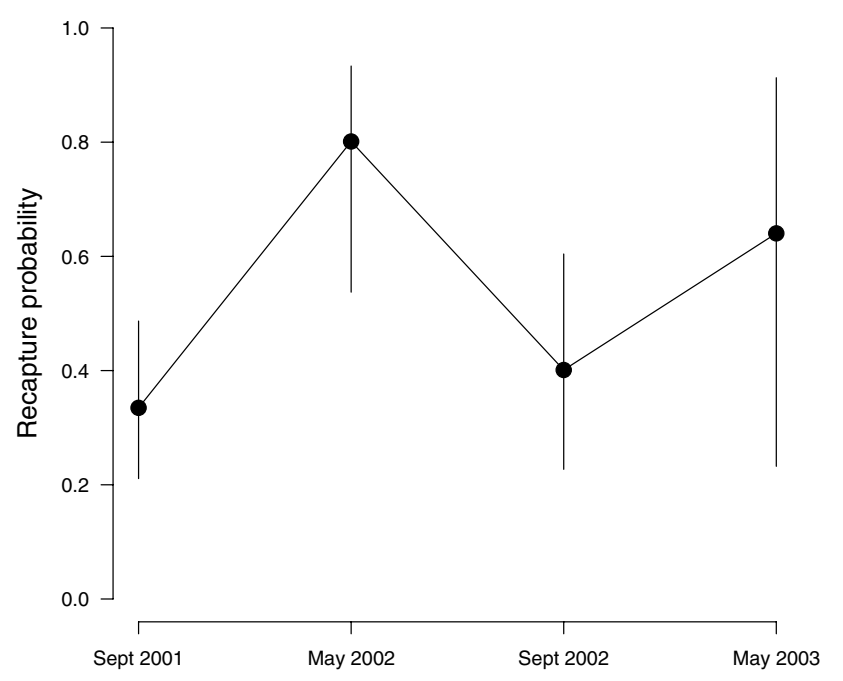

Figure 2

Model averaged recapture probability of Salamandra salamandra from Ellhauser Forest (Germany). The vertical lines show the limits of the unconditional $95 \%$ confidence intervals.

population of Salamandra salamandra [5]. The most plausible explanation for this difference is a relatively high rate of emigration from our study site. The indirect estimate of the probability of emigration showed that about $50 \%$ of the salamanders left the study area. This is a large proportion in light of the strong site fidelity and small home ranges that have been reported for this salamander species $[7,26,27]$. Our analysis suggests that salamanders may be using large home ranges or may have emigrated to neighbouring populations. Indeed, data from the same population show that salamanders in the Ellhauser forest use large home ranges (average $494 \mathrm{~m}^{2}$ ) and moved on average $52 \mathrm{~m}$ and $117 \mathrm{~m}$ per season in 2001 and 2002, respectively. Average distance between successive recaptures was $64 \mathrm{~m}$ and ranged from 4 to $319 \mathrm{~m}$. Thus, many are likely to have left our study area, which had an area of 290 '000 $\mathrm{m}^{2}$ (equivalent to a circle with a radius of $300 \mathrm{~m} \mathrm{[28]).}$ Given the design of our study, we must currently treat migration as a yes/no event where we categorize individuals as "stayers" and "movers". The necessary next step will have to be the better characterization of the movement distribution of salamanders [2].

Further evidence corroborates the hypothesis of high migratory activity in salamander populations. The salamander population studied by [5] showed a large proportion of transients and provided evidence for temporary emigration. Transients are animals that are encountered only once and then leave the study area [29]. Temporary emigrants are salamanders that leave the study area for a while, then return. Because temporary emigrants appear as permanent emigrants in a short-term study such as ours, we cannot discriminate between temporary or permanent emigration. Temporary emigration indeed could result from home ranges that are larger than the study area. Nevertheless, our analysis and the spatial analysis of [28] clearly provide evidence for the fact that terrestrial salamanders can be highly vagile. Further evidence for high migratory activity of $S$. salamandra comes also from population genetic analyses which showed genetic uniformity of salamander populations in an area (the Eifel forest) of more than $225 \mathrm{~km}^{2}$ [14].

These data on migratory activity contrast strongly with the common view of amphibians, and salamanders in particular, being characterized by low vagility $[10,30-34]$, but supports the alternative view that amphibians show high vagility [10]. Closer inspection of mark-recapture studies reveals further evidence that many amphibians appear to migrate substantially. Several studies found evidence for transients [11,15,35-37]. Transients are animals that are encountered only once and then leave the study area [28]. In mark-recapture analyses, transients are detected as violations of assumptions of the traditional Cormack-JollySeber model. Although alternative explanations for the violations of assumptions are possible and favoured by some authors (e.g., effects of marking on survival [37]), nomadic animals on the move that show high vagility and little site fidelity seem a likely explanation, especially if alternative explanations do not apply (e.g., where marking is non-invasive [5]). Proportions of transients can be high. For example, [35] estimated the proportion of transients in the toad Bufo bufo as 0.43 (CI 0.27-0.59) in one year and 0.54 (CI 0.32-0.75) in another year, whereas [11] report an average proportion of 0.35 . Interestingly, there may be variation among populations in their ability to migrate or show "nomadic" behaviour. [5] only found evidence for transients in one of the two populations that they studied. Transients would perhaps be largely equivalent to non-territorial floaters that have been reported for many vertebrate groups, including amphibians [38]. Floaters may be important for population dynamics and conservation [39-41].

The accumulated evidence suggests that amphibians are more mobile than commonly thought. We still need to fully understand the behavioural mechanisms that underlie individual movement patterns as there are several explanations for the observed patterns. Both high rates of emigration and transients may be either due to inappropriate definition of the spatial extent of amphibian populations or may reflect migration between populations. The 
delineation of the study area clearly affects any inference regarding dispersal and needs to be done with great care [3]. In any case, movement behaviour may be a key to understanding the temporal and spatial dynamics of amphibian populations $[10,12,19]$. Rescue effects caused by high numbers of migrants could ensure the persistence of amphibian populations despite the strong fluctuations that characterize amphibian populations [16].

Finally, a better understanding of amphibian movement behaviour is also important for a better understanding of the evolutionary dynamics of amphibians such as patterns of genetic differentiation between amphibian populations. Most of these patterns are interpreted as the result of passive differentiation mechanisms [42]. However, patterns of genetic differentiation should not only be explained by limited dispersal ability of amphibians. The alternative view is that amphibian populations may show high rates of divergence that are adaptive rather than the result of passive processes $[43,44]$.

\section{Conclusion}

Migration to and from populations affects the local dynamics of animal populations. We focus on the demographics of amphibians, a highly threatened group of vertebrates that are commonly thought to show little movement. The analysis of mark-recapture data from a population of salamanders gave remarkably low estimates of apparent survival. These estimates suggest that the probability of emigration was high. Such a high rate of emigration implies that either the spatial extent of salamander populations is greatly underestimated or else migration rates between populations are indeed very high. Both possible interpretations suggest that salamanders are much more mobile than commonly thought. The evidence for transients in mark-recapture studies of a large number of amphibian populations provides indirect evidence for a substantial proportion of transients, i.e., animals on the move. Thus, the results support and extend the emerging new view of amphibians as highly vagile animals. Such a new view means that we would have to reformulate our hypotheses as to how amphibian populations function and suggest that conservationists should strive to maintain migratory activity within and among amphibian populations because migration may be the key determinant of population viability.

\section{Methods}

\section{The species and study site}

Salamandra salamandra is a terrestrial salamander (Figure 3A) that inhabits old broadleaf forest with many small streams. During spring, females migrate to small streams where they give birth to larvae. The streams serve as the habitat for the larvae whereas juveniles and adults are terrestrial. Mating also occurs on land. Salamanders nor-

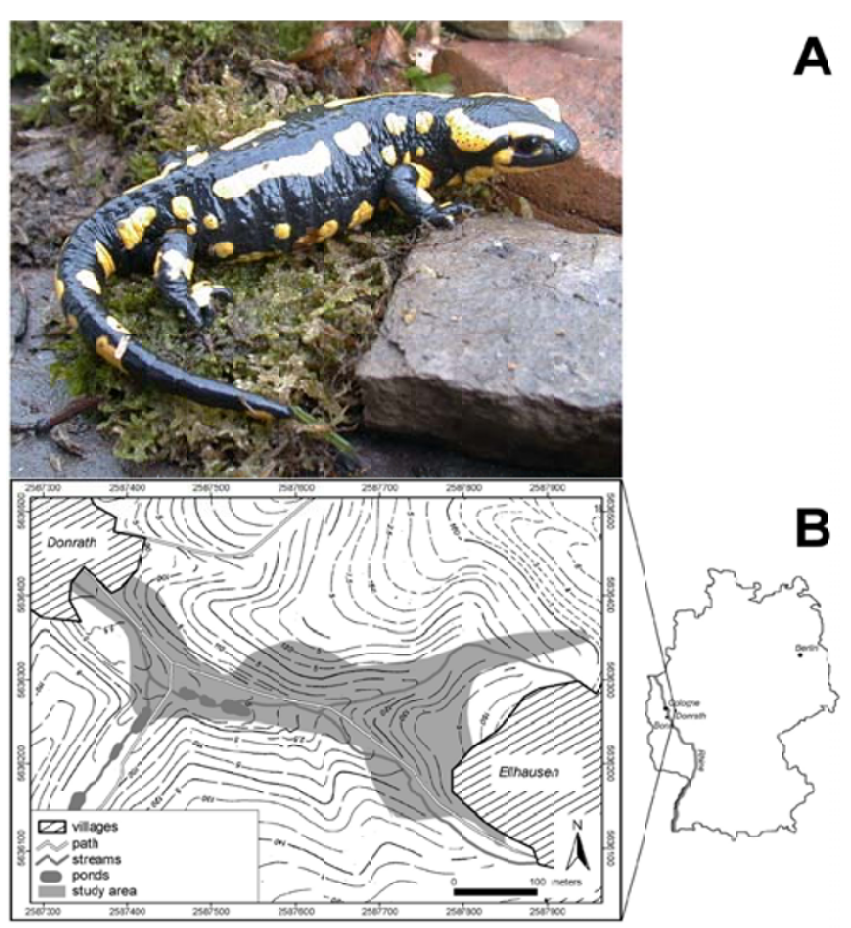

Figure 3

A. Adult fire salamander (Salamandra salamandra) as typically found in the study area. B. Sketch of the study area.

mally start to reproduce after 3-5 years and are long-lived $[5,9]$.

Our study site is part of the Ellhauser Forest located in western Germany $25 \mathrm{~km}$ south-east of Cologne near Donrath within the Bergisches Land (see figure 3B). The forest in which salamanders were found is mainly composed of beech (Fagus sylvatica) and oak (Quercus robur) and represents a typical habitat of $S$. salamandra. Its average altitude is around $200 \mathrm{~m}$ above sea level and the annual precipitation is around $1100 \mathrm{~mm} / \mathrm{m}^{2}$.

\section{Data collection and mark-recapture analysis}

Adult salamanders larger than $12 \mathrm{~cm}$ in total length were fitted with a Euro-I. D. bio-glas transponder (weight 0.09 $\mathrm{g}$, length $12 \mathrm{~mm}$, diameter $2.2 \mathrm{~mm}$ ). For details of the implantation process of PIT tags see [28]. Altogether 86 individuals (59 females, 23 males and 4 individuals of unknown sex) were fitted with PIT tags and released at the site of initial capture.

Field visits were conducted to locate marked individuals. These consisted of repeated intensive searches using torches by 2-3 persons for 5-6 hours from April 2001 until May 2003 in a fixed sub-area of the Ellhauser forest (corresponding to $0.290 \mathrm{~km}^{2}$ ). Each salamander found was scanned with a LID-500 hand scanner and if a trans- 
ponder was detected, both the corresponding transponder code and the coordinates (Gauss-Krueger) of the recapture site were recorded using a differential Global Positioning System (GPS) with an accuracy of three meters. The captures were carried out almost continuously from April to beginning of July, and a second time from September until late October (beginning of hibernation). We pooled all observations from different years conducted in the months of March to July to the occasion "spring" and all captures conducted in the months of September and October to the occasion "autumn". This pooling procedure does not cause bias in survival estimates [45]. The mean capture dates in these five occasions were 7.5.2001, 14.9.2001, 24.4.2002, 28.9.2002 and 2.5.2003. We defined apparent survival from May to September as "summer survival" and apparent survival from September to May as "winter survival".

We analysed the capture-recapture data with CormackJolly-Seber models [46], which allow separate estimates of apparent survival and recapture probabilities. The apparent survival probability $\left(\phi_{\mathrm{i}}\right)$ is the probability that an individual that is in the population at time $i$ is still alive and in the population at time $i+1$. This implies that true mortality and permanent emigration are confounded. The recapture probability $\left(p_{\mathrm{i}}\right)$ is defined as the probability of sighting a marked individual that is alive and in the population at time $i$. The estimation of these parameters requires several assumptions to be met, which can be tested with goodness-of-fit tests $[35,47,48]$. Once a global model has been found to fit the data adequately, nested models can be fitted and their support from the data assessed using Akaike's Information Criterion $\left(\mathrm{AIC}_{\mathrm{c}}[21]\right)$.

We used program MARK [49] to estimate apparent survival and recapture probabilities. We accounted for the unequal time intervals between capture occasions and estimated monthly survival rates.

We fitted a small set of candidate models to the data. Survival was modelled as either constant through time, varying through time (but with no particular pattern) or with a seasonal effect (i.e., summer and winter survival different). The probability of recapture was modelled in the same way: constant, time-varying, or seasonal.

\section{Competing interests}

The author(s) declare that they have no competing interests.

\section{Authors' contributions}

SS initiated this cooperation as a part of his ongoing research on mechanisms of speciation in terrestrial salamanders, provided the capture recapture data as well as manuscript preparation. MS and BRS designed the analy- sis that was performed by MS. BRS drafted the manuscript. All authors read and approved the final manuscript.

\section{Acknowledgements}

The authors thank Sebastian Neubert and Mario Rembold who assisted during the field surveys, Diethard Tautz for logistic support, and Alexander Kupfer and Renata Platenberg for comments on the manuscript. This study was supported by grants of the Deutsche Forschungsgemeinschaft (DFG; Ta99/I6-I and STE II30/3-I) and the "Fondation MAVA".

\section{References}

I. Clobert J, Danchin E, Dhondt AA, Nichols JD, eds: Dispersal. Oxford, Oxford University Press; 2003.

2. Lowe WH: Linking dispersal to local population dynamics: a case study using a headwater salamander system. Ecology 2003, 84:2145-2154.

3. Schaub M, Ullrich B, Knötzsch G, Albrecht P, Meisser C: Local population dynamics and the impact of scale: a case study on different little owl populations. Oikos 2006, I I 5:389-400.

4. Biek R, Funk WC, Maxell BA, Mills LS: What is missing in amphibian decline research: Insights from ecological sensitivity analysis. Cons Biol 2002, I 6:728-734.

5. Schmidt BR, Feldmann R, Schaub M: Demographic processes underlying population growth and decline in Salamandra salamandra . Cons Biol 2005, I 9: I |49-1 | 56

6. Saccheri I, Hanski I: Natural selection and population dynamics. Trends Ecol Evol 2006, $21: 34$ I-347.

7. Joly J: La sédentarité et le retour au gite chez la Salamandra tâchetée. CR Acad Sci 1963, 256:3510-3521.

8. Pough FH, Andrews RM, Cadle JE, Crump ML, Savitzky AH, Wells KD: Herpetology. Edited by: 2. New Jersey, Prentice-Hall; $200 \mathrm{I}$.

9. Thiesmeier B, Grossenbacher K: Salamandra salamandra (Linnaeus, I 758) - Feuersalamander. In Handbuch der Reptilien und Amphibien Europas: Schwanzlurche IIB Edited by: Thiesmeier B, Grossenbacher K. Wiesbaden, Aula Verlag; 2004:I059-II 32.

10. Smith MA, Green DM: Dispersal and the metapopulation paradigm in amphibian ecology and conservation: are all amphibian populations metapopulations? Ecography 2005, 28: I I0-I 28.

II. Perret N, Pradel R, Miaud C, Grolet O, Joly P: Transience, dispersal and survival rates in newt patchy populations. J Anim Ecol 2003, 72:567-757.

12. Petranka JW, Smith CK, Scott AF: Identifying the minimal demographic unit for monitoring pond-breeding amphibians. Ecol Appl 2004, I 4:1065-1078.

13. Funk WC, Greene AE, Corn PS, Allendorf FW: High dispersal in a frog species suggests that it is vulnerable to habitat fragmentation. Biol Lett 2005, I: I3-16.

14. Steinfartz S, Weitere M, Tautz D: Tracing the first step to speciation - ecological and genetic differentiation of a salamander population in a small forest. Mol Ecol 2007, 16:000-000. (doi: I0.1 I I I/j. I365-294X.2007.03490.x)

15. Reading C): Linking global warming to amphibian declines through its effects on female body condition and survivorship. Oecologia 2007, I 5 I: | 25-131.

16. Green DM: The ecology of extinction: population fluctuation and decline in amphibians. Biol Cons 2003, I I I:33 I-343.

17. Schoener TW, Spiller DA: Is extinction rate related to temporal variability in population size? An empirical answer for orb spiders. Amer Nat 1992, 139: I 176-1207.

18. Inchausti $P$, Halley J: On the relation between temporal variability and persistence time in animal populations. J Anim Ecol 2003, 72:899-908.

19. Green DM: Biology of amphibian declines. In Amphibian declines: The conservation status of United States species Edited by: Lannoo M. Berkeley, University of California Press; 2005:28-33.

20. Choquet R, Reboulet AM, Lebreton JD, Gimenez O, Pradel R: U. CARE 2.2 User's Manual. CEFE, Montpellier, CEFE 2005 [http:// ftp.cefe.cnrs.fr/biom/Soft-CR/].

21. Burnham KP, Anderson DR: Model selection and multimodel inference: a practical information-theoretic approach. 2nd edition. New York, Springer; 2002.

22. Seber GAF: The estimation of animal abundance and related parameters. London, Charles Griffin \& Company Ltd; 1982. 
23. Burnham KP: A theory for combined analysis of ring recovery and recapture data. In The study of bird population dynamics using marked individuals Edited by: Lebreton JD and North PM. Basel, Birkhäuser Verlag; 1993:199-213.

24. Schmidt BR: Declining amphibian populations: The pitfalls of count data in the study of diversity, distributions, dynamics, and demography. Herpetol J 2004, I 4: 167-I74.

25. Berven KA, Gill DE: Interpreting geographic variation in life history traits. Amer Zool 1983, 23:85-97.

26. Denoël M: Phénologie et domaine vital de la Salamandra salamandra terrestris (Amphibia, Caudata) dans un bois du Pays de Herve (Belgique). Cahiers Ethol 1996, 16:291-306.

27. Rebelo R, Leclair MH: Site tenacity in the terrestrial salamandrid, Salamandra salamandra . J Herpetol 2003, 37:440-445.

28. Schulte U, Küsters D, Steinfartz S: A PIT tag based analysis of annual movement patterns of adult fire salamanders (Salamandra salamandra) in a Middle European habitat. AmphibiaReptilia 2007, 28:000-000.

29. Pradel R, Hines JE, Lebreton JD, Nichols JD: Capture-recapture survival models taking account of transients. Biometrics 1997, 53:60-72.

30. Gill DE: Effective population size and interdemic migration rates in a metapopulation of the red-spotted newt, Notophthalmus viridescens (Rafinesque). Evolution 1978, 32:839-849.

31. Sinsch U: Migration and orientation in anuran amphibians. Ethol Ecol Evol 1990, 2:65-79.

32. Blaustein AR, Wake DB, Sousa WP: Amphibian declines: Judging stability, persistence and susceptibility to local and global extinctions. Cons Biol 1994, 8:60-7|.

33. Stebbins RC, Cohen NW: A natural history of amphibians. Princeton, Princeton University Press; 1995.

34. Beebee TJC: Conservation genetics of amphibians. Heredity 2005, 95:423-427.

35. Schmidt BR, Schaub M, Anholt BR: Why you should use capturerecapture methods when estimating survival and breeding probabilities: on bias, temporary emigration, overdispersion, and common toads. Amphibia-Reptilia 2002, 23:375-388.

36. Frétey T, Cam E, Le Garff B, Monnat JY: Adult survival and temporary emigration in the common toad. Can J Zool 2004, 82:859-872.

37. Scherer RD, Muths E, Noon BR, Corn PS: An evaluation of weather and disease as causes of decline in two populations of boreal toads. Ecol App/ 2005, I5:2150-2160.

38. Mathis A: Territories of male and female terrestrial salamanders: costs, benefits, and intersexual spatial associations. Oecologia I99I, 86:433-440.

39. Durell SEA le V dit, Clarke RT: The buffer effect of non-breeding birds and the timing of farmland bird declines. Biol Cons 2004, 120:375-382.

40. Lopez-Sepulcre A, Kokko H: Territorial defense, territory size, and population regulation. Amer Nat 2005, 166:317-329.

41. Penteriani V, Otalora F, Ferrer M: Floater dynamics can explain positive patterns of density-dependent fecundity in animal populations. Amer Nat 2006, 168:697-703.

42. Larson A, Wake DB, Yanev KP: Measuring gene flow among populations having high-levels of genetic fragmentation. Genetics 1984, 106:293-308.

43. Skelly DK: Microgeographic countergradient variation in the wood frog, Rana sylvatica. Evolution 2004, 58:160-165.

44. Van Buskirk J, Arioli M: Habitat specialization and adaptive phenotypic divergence of anuran populations. J Evol Biol 2005, 18:596-608.

45. O'Brien S, Robert $\mathrm{B}$, Tiandry $\mathrm{H}$ : Consequences of violating the recapture duration assumption of mark-recapture models: a test using simulated and empirical data from an endangered tortoise population. J Appl Ecol 2005, 42: 1096- I I04.

46. Lebreton JD, Burnham KP, Clobert J, Anderson DR: Modeling survival and testing biological hypothesis using marked animals: a unified approach with case studies. Ecol Monogr 1992, 62:67-II8.

47. Burnham KP, Anderson DR, White GC, Brownie C, Pollock KH: Design and analysis methods for fish survival experiments based on release-recapture. American Fisheries Society Monograph Number 51987.
48. Schaub M, Gimenez O, Schmidt BR, Pradel R: Estimating survival and non-random temporary emigration in the multistate capture-recapture framework. Ecology 2004, 85:2 107-2 II 3 .

49. White GC, Burnham KP: Program MARK: survival estimation from populations of marked animals. Bird Study 1999, 46:120-39.

Publish with Bio Med Central and every scientist can read your work free of charge

"BioMed Central will be the most significant development for disseminating the results of biomedical research in our lifetime. "

Sir Paul Nurse, Cancer Research UK

Your research papers will be:

- available free of charge to the entire biomedical community

- peer reviewed and published immediately upon acceptance

- cited in PubMed and archived on PubMed Central

- yours - you keep the copyright

Submit your manuscript here:

http://www.biomedcentral.com/info/publishing_adv.asp
BiolMedcentral 